Wiesław Wójcik

Jan Długosz University, Częstochowa, Poland

ORCID: 0000-0001-8132-3212

e-mail:wwoj100@gmail.com

\title{
The Problem of Intuition in Mathematics in the Thoughts and Creativity of Selected Polish Mathematicians in the Context of the Nineteenth-Century Breakthrough in Mathematics
}

\section{Introduction}

Intuition is attributed to various properties. It is rather widely accepted as a kind of cognition and an essential element of the cognitive process. All attempts to replace it with formalization or rationalization ended with the discovery of the next, "layers" of intuition, its functions and meanings. The formalization itself turned out to be strongly associated with intuition, and, even in rational thinking and cognition, intuition was found as it is necessary component. It is assumed, as opposed to discursive cognition, that it is direct, which means that it is not using inferences, proofs, symbols and language. This cognition uses images, it is sensible and holistic. Often, its action is not fully conscious and seems to be a part of the subconscious. It often appears as a component of creativity in the form of inspirations, revelations, and sudden discoveries. Sometimes it leads infallibly to the goal, but often also deceives; intuition is attributed to both, feelings and reason. It is spread somewhere between the mystical (extrasensory), abstract and concrete, sensual and individual states. 
Despite its ambiguous status, intuition also appears in cognition and mathematical creativity. It seems that its elimination from mathematics (and such attempts were made) is not possible, and striving towards its complete removal has led to adverse effects, e.g. blocking further development of science. On the other hand, in the situation of building new mathematical concepts and theory, relying on it sometimes led to mistakes, generated contradictions, paradoxes and antinomies. Therefore, the analysis of presence and significance of intuitive cognition in mathematics is necessary and, as I will show, also allows for a better understanding of the phenomenon of intuition as such.

Intuition occurs in mathematics in four areas: discovery, understanding (concepts, proofs), justification (specificity of mathematical proofs), and acceptance or rejection (substantive, but also didactic context, as well as, more broadly - sociocultural). ${ }^{1}$ I will focus on contexts of understanding and justification, where the occurrence of mathematical intuition is less obvious and also indicates the specifics of mathematics. Especially significant for these studies is the turn of the nineteenth and twentieth century's, when new mathematical theories were emerging. In the paper, I do not study the dispute between formalism and intuitionism that took place at that time, nor do I analyze the directions in the then philosophy of mathematics (formalism, intuitionism or constructivism). To a large extent, they were inspired by transformations in mathematics and were an attempt to understand the situation. The paper attempts to show the place where these transformations took place, how creators had struggled with their previous habits and intuitions, and how new mathematical intuitions were shaped. The approach to the problem implemented in the article is similar to the one presented by Jerzy Pogonowski in a series of articles on mathematical intuition. It is about exploring mathematical intuition in action, showing how it changed during the development of mathematics when new theories and objects appeared.

The paper is de facto devoted to the work of Polish mathematicians from the beginning of the twentieth century and their reflection on the presence of intuition in mathematics. Their example clearly shows the phenomenon of transformations made then, and the struggles of old and new intuitions in mathematics. I would like to further analyze the views on the mathematical intuition which are significant to the origin of the

1 Cf. Mieczysław Omyła, "Intuicja w naukach formalnych”, Edukacja Filozoficzna 50 (2010): 139-155.

${ }_{2}$ Cf. Jerzy Pogonowski, Intuicja matematyczna $w$ działaniu, http://logic.amu.edu. pl/images/5/54/Mo70jp.pdf, access: 11.10.2019; idem, "Kilka uwag o intuicji matematycznej", Filozofia Nauki XX, 2/78 (2012): 107-113; idem, "Mathematical intuition a few remarks", Investigationes Linguisticae XXIV (2011): 1-24. 
Polish school of mathematics and to give it a proper character. They were put forward by four Polish mathematicians: Jan Śleszyński (1854-1931), Jan Łukasiewicz ${ }^{4}$ (1872-1956), Zygmunt Janiszewski ${ }^{5}$ (1888-1920) and Hugo Steinhaus $^{6}$ (1887-1972). On their examples, I will show how mathematical creativity (and intuitive and formal cognition in it) intertwines with reflection on mathematics.

Polish mathematicians and logicians mentioned above referred to several traditions and research programs in their studies. One of most important is the idea of Bernard Riemann and the German school in Göttingen (R. Dedekind, F. Klein, D. Hilbert) that followed him, or the research of the French school with H. Poincaré and H. Lebesgue at the forefront. They also referred to the research programs and concepts of $\mathrm{G}$. W. Leibniz, G. Frege and the study in the field of algebraization of logic by Peirce, Schröder and Couturat as well as the concepts of Russell and Whitehead.

The result of these analysis will also be a description and a fragmentary understanding of the breakthrough that took place in mathematics at the turn of the nineteenth century. Furthermore, the analysis will also allow understanding the difficulties that arise when acquiring new mathematical concepts and arguments (the specifics of intuition and mathematical creativity). The research, by pointing to the universal nature of mathematical intuition and showing the relations between different types of intuition, will also allow deepening the study on the very phenomenon of intuition in cognition.

${ }^{3}$ He was a Polish mathematician, logician, philosopher and one of the pioneers of mathematical logic in Russia and Poland. He showed the continuity of development of logic, starting from classical logic to mathematical logic. He also developed a monograph, especially important for showing the relationship between the formal structure of proof and the use of intuition in it (Teoria dowodu, 1925-1927).

${ }^{4}$ He used logical analysis in researching the foundations of empirical sciences and mathematics (he analyzed the law of noncontradiction, the law of excluded middle, the law of causality, the idea of probability, and others). This research led him to the creation of a logical theory of probability, three-valued logic, many-valued and modal logics. He also conducted metatheoretical studies on logic, and more broadly on axiomatic-deductive systems.

${ }^{5}$ He was not only a prominent mathematician and co-creator of Warsaw School of Mathematics, but also a philosopher of science, studying the foundations of mathematics and designing its development.

${ }^{6}$ He was active in the field of pure mathematics, but also in its applications and popularization. An important area of Steinhaus's activity was to show the universal nature of mathematics. It was showing its presence in the world and in other sciences and also expressing mathematical truths other than formal methods (visualized mathematics, pictorial mathematics). 


\section{Mathematical Intuition vs. Logic and Hidden Harmony}

In the mid-nineteenth century, an indication of a breakthrough in mathematical and physical sciences can be observed. The entry of science into new areas, despite many successes and hopes, also gave birth to a whole lot of new problems and difficulties. They grew gradually and reached a critical condition in the mid-nineteenth century. It turned out that intuition formed on the basis of previous theories and experience is insufficient and leads to many paradoxes. This forced a reflection on science, its foundations, and especially on the concepts and methods that, despite intuitive obviousness, generated difficulties. Examples of such are the concept of number (extended to irrational and complex numbers), continuity, limit, function, infinite series, derivatives, integrals. They were used universally, but yet they lacked the accuracy needed in mathematics. It was necessary to rethink and to define the concepts of size, space, curve, surface, as well as variability, function, identity, constructability, computability, continuity, limit and continuum. It turned out that work on new theories and definitions led to shaping new intuitions. This new situation in mathematics has brought about reflection on the very phenomenon of mathematical intuition. A particular challenge was to examine the foundations of theories that seem to have been well-grounded for centuries: geometry (in the face of the appearance of Non-Euclidean geometries), arithmetic (construction of Non-Archimedean arithmetic) and algebra (the emergence of Galois theory and significant development of algebraic methods). It is only then that concepts are born, becoming the foundation of mathematics and other sciences: the concept of a set (including the infinite set), group, manifold and invariant.

Polish mathematicians and philosophers significantly contributed to this research. They were the creators or co-creators of new mathematical theories and, in many cases, they analyzed the foundations of mathematics and other sciences as well as their formalization (including axiomatization and mathematization). It was a formal analysis (often a logical analysis), using the methods of new mathematical theories and analytical philosophy. Polish reflection referred to key discoveries in mathematics and physics, but these discoveries did not make them absolute and saw the need for authentic philosophical reflection on the sciences (which was not so obvious in the era of scientism and positivism). Polish scholars referred to (newly emerged) theories: mathematical logic, set theory, topology, measure theory, functional analysis. They developed them, studied their foundations and the foundations of geometry, arithmetic, logic, probability theory and mathematical analysis. With the help of logical analysis, they studied the concepts of causality, consistency, probability, truth, discourse, relations, and more. In this way, many new 
ideas, concepts, and theories were created, including semantic theory of truth, many-valued and modal logics, theory of sets in collective sense and discursive logic. Continuity in the development of science was also noted and the relevance of achievements of previous eras to modern science was pointed out. ${ }^{7}$

For many Polish mathematicians, the inspiration which led to reflection on mathematics was Henri Poincaré (1854-1912). According to Poincaré, the main goal of science is to explore the hidden beauty, harmony of the world, which is accompanied by recognizing and constructing the beauty of simple facts and mathematical formulas. It has its groundwork in the instinctive desire for beauty which strengthens the selfless search for the truth. The usefulness of science appears as the natural fruit of this search. ${ }^{8}$ When carrying out mathematical proof, it is important to feel a general course of reasoning (not memory or proficiency in calculations), and so intuition of order in which the elements of proof are arranged. This intuition allows us to discover those hidden harmonies and relationships that operate in the conscious work of a scholar, that are present in the formal structure of proof, but also in the work of the subconscious and material reality. When he drew closer to discoveries with the participation of the subconscious, Poincaré observed his creative process with great commitment. A good idea suddenly appeared in the mind as a glare. This shows the unity of the world in all its areas. This linking element is, in fact, mathematical intuition, which enables creativity and exploration of the world. From the fact that intuition is an essential element of the scholar's work, Poincaré concluded that it is not possible to fully formalize mathematics (and even more so in other sciences) and reduce it to formal logic.

The presence of mathematical intuition can be observed in three fields: building tools for exploring nature, stimulating philosophical thinking, and showing the beauty and unity of the edifice of knowledge. The precise, accurate, and sufficiently rich language of mathematics allows the natural sciences to grasp the diverse and complex relationships discovered in nature. Enclosed in the framework of general formulas, it becomes a harmonious arrangement of phenomena. ${ }^{9}$ According to Poincaré, mathematical analogy (the power of precise language,

${ }^{7}$ Important examples are the studies by Jan Śleszyński and Jan Łukasiewicz on the history of logic and observation that mathematical logic is the next stage in the development of logic. Classic logic can be expressed using the language of new logic.

${ }^{8}$ Henri Poincaré, Nauka i metoda, transl. M. H. Horwitz (Warszawa: G. Centnerszwer i S-ka, 1911), 11.

9 Idem, "Sur les rapports de l'analyse pure et de la physique mathematique", in: Verhandlungen des ersten internationalen Mathematiker - Kongresses (Leipzig, 1898); T. S. Dickstein, "Związki pomiędzy analizą i fizyką matematyczną", Mathematical News 1 (1897): 184. 
simplicity and pure form) is used to show similarities, relationships between various fields of knowledge and between science and reality..$^{10} \mathrm{It}$ is the most important element of mathematical intuition, it indicates the incomprehensible (suprarational) relationship of reality and thought. It allows to look at mathematics as a work of art and, at the same time, discover and see profound harmony in reality. ${ }^{11}$

These threads are developed by Polish mathematicians. In the introduction to the Guide, ${ }^{12}$ Janiszewski, trying to show the value and sense of abstractness, generality and accuracy of mathematical truths, notes that thanks to these features it is possible to build an internal, coherent world. It has value in itself and, at the same time, it is capable of building relations with the external world (however, possible applications are not the purpose of mathematical activity). Mathematical activity cannot be reduced to some game or amusement; it is much more than that. The truths discovered by mathematics extend our cognition and are connected with the rest of our knowledge and the world in a way which is hard to predict. The field of mathematics is constantly expanding and we cannot trace its further paths.

Only the intuition of mathematical beauty learned through the experience of tracking and proving mathematical truths and also a certain innate predisposition allows capturing the consistent edifice of mathematics. It is a kind of art - bold, pure and sublime, which exceeds the boundaries of imagination, and yet (maybe due to this) refers to reality. It is difficult to describe and express what this intuition and beauty is to someone who has not experienced it himself. ${ }^{13}$

Similarly, Steinhaus, referring to the beauty of mathematics, notes that several elements are needed in order to see it. First of all, the condition of its perception is to capture the historical continuity and order of discoveries. Individual discoveries entail others, the conceptual framework is therefore expanding and we are dealing with the transmission of basic meanings and content. Thus, mathematical intuition is being shaped. This allows him to see the harmony of issues, questions and solutions. He notes that accuracy is needed to solve various issues, but it is not an end in itself. Mathematics solves problems, it is sensitive to reality and thus cannot be completely specified or formalized. It cannot be reduced to a formal game of symbols. "But everyone knows that the scientific value of even the most beautiful chess endgame

${ }^{10}$ Ibidem, 186.

${ }^{11}$ Idem, Wartość nauki, transl. L. Silberstein (Warszawa: G. Centnerszwer i S-ka, 1908), 94.

12 Zygmunt Janiszewski, “Wstęp ogólny”, in: Poradnik dla samouków (Warszawa: A. Heflich, St. Michalski, 1915), 3-27.

${ }^{13}$ Cf. ibidem, 11-16. 
is nothing compared to the humblest theorem of elementary geometry, and this is because the game called geometry is a confrontation of a man with the world around him and every victory in this game has lasting significance for the human race" ${ }^{14}$ Consequently, there is a relationship between mathematics and the external world, and it is being revealed just when mathematics is developing. Further analogies are being built between rational constructions and reality, which enable us to see rationality and harmony in history and in the world. Mathematical intuition, which was shaped through centuries, allows making non-trivial generalizations. This intuition comes from human nature and transcends it somehow, but does not break connection with it. It makes mathematical proofs understandable, important and beautiful. In a purely formal way and based on total accuracy (according to established algorithms), a machine could generate any number of meaningless "theorems". Then, however, man, beauty and true creativity would disappear from the area of mathematics. ${ }^{15}$

Also Śleszyński analyzes mathematics (and logic) and describes its structure, in which both intuition and logic play an important role. According to him, every science using the deductive method has two parts: static and dynamic. In the static part, we are only looking for a logical relationship, which is captured by the system of sentences related to each other by proofs. The search for this relation is, as Śleszyński noted, the most important problem of science. It is also the main didactic and moral goal of every human being. Through analyzing Aristotle's logic, he points to the syllogism discovered by the Greek philosopher as a necessary relation between postulates (premises) and the conclusion. "A wonderful relation, however, is not based on any violation, criminal law, or any seriousness; it is in us! You need to nourish and strengthen the sense of this relation, you need to develop gentleness and sensitivity to $i t^{\prime \prime}{ }^{16}$ Shaping this sensitivity (moral, intellectual and didactic) builds a scientific intuition which allows us to recognize facts and relationships that are scientifically and cognitively valuable.

In the dynamic part, science is creativeness and a dynamically developing system of hypotheses, intuitions and philosophical as well as psychological and other issues. For this reason, no science (even mathematics) can be reduced to purely formal logic. Only "technical logisticization" is possible, and thus, the use of established logical relations for

${ }^{14}$ Hugo Steinhaus, "O ścisłości matematycznej", in: Między duchem a materia pośredniczy matematyka (Warszawa-Wrocław: PWN, 2000), 55.

${ }^{15}$ Ibidem, 57-58.

${ }_{16}$ Jan Śleszyński, Teoria dowodu, vol. 1, ed. S. K. Zaremba (Kraków: Nakładem Kółka Matematyczno-Fizycznego U.U.J., 1925), 9. 
the analysis of proof, presentation of complete proof, and their logical abbreviations (for didactic purposes and simplification of the message).

The definitions and theorems (not to mention proof) are intricate, and for those who start their adventure with mathematics, they seem artificial and unnecessary. Historical perspective allows showing questions and problems that led people to these formulations. You can see the path of the greatest artists struggling with their own intuition, misunderstanding, and gradual achievement of later precision. ${ }^{17}$

In this shaping of the right intuitions that allow us to show the content and deductive power of proof and the correct shortening of proof, logical laws are important (these are also research methods). One of them is the law of transposition, giving the opportunity to replace proof by contradiction (reductio ad absurdum) with strictly deductive reasoning. Proof by contradiction often significantly simplifies reasoning, but it puts the listener in front of the experience of paradox and mystery (we received a contradiction but the mechanism of argumentation itself is covered).

For Śleszyński, the modus ponens law $-((p \rightarrow q) \wedge p) \rightarrow q-$ is crucial. This law shows that in some cases it is possible to reject logical links in mathematical proofs (not to use them as premises), but they can used only as methods of inference. Therefore, the proof is shortened, but logical laws are constantly used "in the background" - they become the methodological skeleton of proof and the force shaping mathematical intuition. Śleszyński examines the correctness of mathematical proofs with this method. Proofs used in mathematics are usually incomplete, i.e. the ones in which not all of the links of proof are explicitly listed. The proof has "gaps" which are usually shortcuts that are easy to complete. However, such complementations are not always possible. Often, attempts to logically complement some mathematical proofs ended in failure, while those proofs that were believed to be incorrect could easily be presented in the form of complete proofs. Therefore, a logical analysis of proof should separate individual links of proof, determine methods of proof (which may differ from the currently "binding") and see in them the appropriate logical laws. These logical laws can, in turn, be included in the proof as premises for reasoning, and then the correctness (or their falseness) of the proofs can be shown.

17 Idem, “Rozwój pojęć nieskończonościowych”, in: Poradnik dla samouków (Warszawa: A. Heflich, St. Michalski, 1923), 54-55. 


\section{Building New Mathematical Intuitions. The Universal Nature of Mathematical Intuition}

New constructions, objects, and mathematical theories emerging at the turn of the twentieth century, often went beyond the intuitions formed earlier in the development of mathematics.

It is enough to just mention the Cantorian set (uncountable and dense in itself, but nowhere dense), the continuous function which is nowhere differentiable (i.e. not having a tangent at any point), the curve filling the square, the curve on a plane being the edge of more than two areas, the indecomposable continuums (i.e. those that cannot be divided into the sum of two proper, non-empty subcontinues), the sets whose proper part is equipotent to the whole.

Janiszewski notes that these facts are not paradoxical - they only go beyond the imagination and common intuition. If we look into their logical and mathematical structure, we will see that the constructions which are carried out are correct, but they require the development of new mathematical imagination and intuition.

An important field of research at the Warsaw school of mathematics was geometric topology, including constructions and the study of indecomposable continuum. Janiszewski undertook study in this field started off by a Dutch mathematician, Brouwer, who in 1909 constructed the first indecomposable continuum. ${ }^{18} \mathrm{He}$, in fact, constructed sets whose properties contradicted theorems proved by Schoenflies (works from 1903 to 1906 on topology of plane and, which are an attempt to characterize plane curves, e.g. as the boundaries of areas). The new constructions (indecomposable continuum) undermined what seemed obvious to Schoenflies, i.e. that each closed curve can be split into two arches and that each closed curve on the plane is the boundary of two areas. The intuition, which is formed on the common experience, is not able to imagine an indecomposable continuum. Such indecomposability seems to contradict the essence of the continuum. Brouwer sought to give the set-theoretical (which is the most general and based on set theory) description of the "curve". Due to such descriptions, we can avoid contradictions and errors that resulted from the use of previously developed geometric intuitions. Only sufficiently general and "meta-geometric" descriptions will give the opportunity to free yourself from these intuitions and build a new way of thinking (including a new intuition).

What was this change in mentality based on? In the ancient paradoxes about size (including the continuum as something that can be divided

${ }^{18}$ He did this in the work "Zur Analysis Situs", which appeared in Mathematische Annalen in 1910 (422-434). 
indefinitely and where parts touch each other), a dilemma associated with the structural elements of continuum arose. It is built either of indivisible (discrete) points or of smaller continua. In both cases we have a contradiction: in the first case, we would receive continuous quantity from the discrete elements, and in the second, we would never get to the components of the construction (reconstruction) due to the endless division of the continuum.

This original intuition was overcome by the notion of the distributive set (developed in Cantor's set theory). The set combines into the one whole any "indivisible" elements and can simultaneously assume very diverse properties. As it turned out, defining the continuum as a set (of points) which fulfills two properties (connectedness and compactness) defined in the language of the new theory removed the previous paradox.

Janiszewski defined next geometric objects according to this method. He started this assignment in his doctoral dissertation Sur les continus irréductibles entre deux points (1911, Paris, supervised by Lebesgue). He gives strict definitions of the interval, curve, surface (and other geometric concepts) by set-theoretical and topological methods and then generalizes them. He introduces the concept of the "arc" (as a topological generalization of the interval, it is a homeomorphic image of an interval) and the concept of "continuum of condensation" (a nowhere dense continuum having more than one point) and constructs an indecomposable continuum (continuum that cannot be decomposed into two proper subcontinua). The arc is the simplest multipoint continuum and can be characterized as follows: it is a continuum which is locally connected ${ }^{19}$ and irreducible between two points. ${ }^{20}$ Janiszewski also noted that the arc can be defined as an irreducible continuum between two points that does not contain a subcontinuum of condensation. ${ }^{21}$

At the Mathematicians Congress in Cambridge (1912) he presented (looking for a precise definition of curve) a sketch of the construction of an extremely paradoxical curve that does not contain arches (the lecture Über die Begriffe 'Linie' und 'Flache'). It was "paradoxicall from the point of view of the mathematical intuition of that time because the concepts of the curve and the arc seem inseparably connected with one another. In his habilitation thesis, On the cutting of the plane by continuum (Lviv, 1913), he explores the topology of the plane and indicates its

${ }_{19}$ Any space is locally connected if in each point of this space exists any unrestricted small and connected neighborhood.

${ }^{20}$ Any continuum is irreducible between two points if it is the smallest continuum including this points.

${ }^{21}$ Zygmunt Janiszewski, Sur les continus irreductibles entre deux points. These (Paris: Gauthier-Villars, 1911), 53. 
key property (the so called Janiszewski's property, which allows for the internal, topological characteristics of the two-dimensional sphere). By introducing the generalized (topological) concept of the curve and the sphere and their topological characteristics, he again manages to avoid a sense of paradox.

Therefore, the general scheme of obtaining and defining new mathematical objects, that allow overcoming "false" intuitions and building new ones, is as follows:

1. We assume some mathematical theory as the basis for construction and definition (in this case, it is set theory).

2. We generalize a given object (e.g. a geometric object) within the considered theory (in this case, we have topology).

3. We are looking for the minimum amount of properties needed to define a given object in such a way to preserve "good" intuitions and overcome "improper" ones.

4. In these studies, we use tools of mathematical logic (logical analysis).

The subject of study of the new geometry (topology) understood in this way is no longer space (visible, physical, as a "place"), but a manifold of points (understood as a distributive set). The notion of manifold (Mannigfaltigkeit), introduced by Bernard Riemann in the 1850s, can be understood very generally. Let us see how Riemann's mathematical intuition "works" while getting the mathematical concept of manifold. Kant in the Critique of Pure Reason notices that the manifold of images creates a synthetic unity based on the a priori ability of the intellect to connect and reduce the manifold of images to the unity of apperception. This power of synthetic unity is the highest in all human cognition..$^{22}$ Following this lead, Riemann considers any arrangement of elements having the simplest possible geometric structure to be the manifold. He noticed that in this original intuition these elements could also be any arbitrary elements taken in an abstract way, for example, a set of colours and a set of all positions of spatial objects of sensual perception. the manifold was also a set of functions defined in a given domain or a set of all possible figures of a given closed area of space. ${ }^{23}$

As Janiszewski notes, the manifold is what "can be captured by thought, which is the basis of logical, deductive theory. This can only be a set of axioms; axioms just define the manifold, create the subject

${ }^{22}$ Immanuel Kant, Critique of pure reason, transl. P. Guyer, A. W. Wood (Cambridge: Cambridge University Press, 1998), 204-214.

${ }^{23}$ Roberto Torretti, Philosophy of Geometry from Riemann to Poincaré (Dordrecht-Boston-Lancaster: Reidel Publishing Company, 1978), 85. 
of mathematical research" ${ }^{24}$ In this way, the concepts of geometry lose their original imaginative content, and their logical content is extracted and preserved.

If, on the one hand, we apply a critical study of the foundations with the help of logical tools, and on the other, build maximum general theories (such as set theory, group theory, topology) and develop the axiomatic method, we can see new relations between theories, we can also transfer entire theories from one domain to another (which takes place e.g. between topology, set theory and group theory). It also allows us to take an in depth look into the essence of a theory by investigating (in axioms) those properties on which this theory is based, introduce new concepts (they are sought to satisfy certain conditions for e.g. Lebesgue's integral), and abstract ones, from all individual properties that make up a given theory and examine only a logical form. In this way, we receive a program of searching for common or analogous structures of various fields of science and for building the unity of science based on mathematical methods.

Due to a significant development of mathematics at the beginning of the twentieth century, to bring new mathematical theories and new content to students, key changes in its teaching were made. In 1905, at the Congress in Merano, the so-called Merano Program was created in which the role of mathematics in explaining the nature and building culture was included in education. It was about a broader use of the principle of visibility, referring to the child's natural intuition, developing spatial imagination and functional thinking as well as developing the ability to see mathematical structures in nature and to show relations between different disciplines of science. ${ }^{25}$

A little further goes the proposal that Hugo Steinhaus gave in the early 1920s. ${ }^{26} \mathrm{He}$ called his educational program "The Archimedes Project". ${ }^{27}$ This project is concerned with teaching mathematics so that it becomes present in real problems, so that mathematical knowledge passed on in the teaching process has a real and substantial impact. In order to make education sensible, the knowledge that is being passed on must find applications in various areas of life. Mathematicians must appear in the society in various areas of life and the economy (a mathemati-

${ }^{24}$ Zygmunt Janiszewski, “Podstawy geometrii”, in: Poradnik dla samouków, vol. 1 (Warszawa: A. Heflich, St Michalski, 1915), 407.

${ }^{25}$ Cf. Alicja Molęda, Zenon Piesyk, "Przegląd zmian programów nauczania matematyki w szkole podstawowej w latach 1963-1990 w Polsce", Acta Universitatis Lodziensis. Folia Mathematica, 6 (1993): 25-56.

${ }^{26}$ Cf. Hugo Steinhaus, Czem jest a czem nie jest matematyka (Lwów: Księgarnia H. Altenberga, 1923).

27 Idem, Między duchem a materia pośredniczy matematyka (Warszawa-Wrocław: PWN, 2000), 250. 
cian does not have to be only a teacher or a scholar) where strategic planning and optimization are needed (thus, practically everywhere). This must bring clear social and economic benefits.

Mathematics shapes intellectual sensitivity and intuition, that allows us to see hidden beauty, order and harmony and bring them into existence. Mathematics that is alive is a free activity of the mind, it is an unrestricted external reality (a conscious world, an authority), and its strength depends on the imagination, ingenuity, and giving into the rigors of strict and consistent thinking (deduction).

Mathematical thinking is more than symbolic, it works through various means of expression. To show its universal character, Steinhaus writes books on math containing pictorials (not only for children). ${ }^{28}$ Mathematics works in every world, pictorial too, so that it can also be seen. In teaching mathematics, one must show the way from mathematics to reality (in its various forms). This path is the essence of the mathematical method which allows finding deep analogies between seemingly quite separate situations and fields.

\section{The Place of Mathematical Intuition in Building Scientific Syntheses and Studying the Foundations}

In Polish scientific (mathematical, philosophical and logical) schools, the openness of logical and mathematical procedures was strongly emphasized. Mathematical and logical theories are constantly evolving and cannot be reduced to rigid and established procedures. An indispensable feature of science, and this applies especially to exact sciences, is free creativity. Science cannot be simply reduced to searching for the truth or thirst for knowledge; nor is it only based on building general scientific laws or for practical applications. It does not just obtain justification. It is not for proofing methods, creating a grid of exact and adequate concepts for verifying reality, verifiable hypotheses, or even showing precise and logical reasoning. Łukasiewicz notes that "the goal of the science is to build syntheses that meet the universal intellectual needs" ${ }^{29}$ Moreover, logic and mathematics must be constantly confronted with reality and experience. They cannot replace this reality; therefore, mechanisms for building a continuous and creative relationship between them must be assembled. For this, the scholar's intuition is necessary which, on the one hand, does not allow the separation of science from reality and pushing

${ }^{28}$ Idem, Kalejdoskop matematyczny (Lwów: Książnica Atlas, 1938); there were several Polish editions of the work and many in foreign languages.

${ }^{29}$ Jan Łukasiewicz, "O twórczości w nauce”, in: Z zagadnień logiki i filozofii (Warszawa: PWN, 1961), 74. 
it into the rut of nominalism, and on the other, shows the strength of its autonomy.

Logic together with mathematics could be compared to an intricate network, which we cast to the immeasurable phenomena, in order to catch pearls of scientific synthesis from it. (...) These syntheses include true claims about facts; they mainly arouse intellectual needs. These are reconstruction elements. But creative claims also belong to syntheses; they meet intellectual needs. These are structural elements. Both elements unite together thanks to the relation of logical entailments. ${ }^{30}$

Here, we have an interesting combination of two elements necessary for scientific activity: searching for logical relations of consequence and building a reference both to reality as a source and to scientific constructions. In both cases, mathematical intuition works enabling, on the one hand, the concretization of the results of theory, and the appropriate process of abstraction, generalization and universalization on the other (finding the "final" foundations of science and its synthesis).

A good example is Łukasiewicz's work on logical theory of probability and on multivalent and modal logics. ${ }^{31}$ On the one hand, the theories obtained are the result of a logical analysis of basic philosophical concepts and principles such as the principle of contradiction, the principle of the excluded middle, the principle of divalence, as well as the concepts of possibility, free creativity and necessity; and on the other hand, the belief that these logic laws are not final and can be modified or removed from the logic system. This belief, which was the result of historical research, philosophical and logical experience together with creative intuition based on it, accompanied Łukasiewicz in discovering further theories and ideas. In the case of the principle of bivalence (each sentence is either true or false), he writes: "This principle, precisely because it underlies logic, cannot be proved. You can only believe in it, and whoever seems obvious will believe it. Personally, it doesn't seem obvious. Therefore, I am not allowed to accept this principle and accept that, apart from truth and falsity, there are other logical values." ${ }^{22}$ This is how multi-valued logic is born, based on rationally justified intuition (belief).

At some point in the development of mathematics, when new, "nonqualitative" theories arose, its ability to look at all knowledge appeared. The process of mathematization of logic, probability calculus, statistics, economics and many other areas of knowledge, had begun. I think the

${ }^{30}$ Ibidem, 73-75.

31 Cf. Jan Łukasiewicz, Elementy logiki matematycznej (Warszawa: Komisja Wydawnicza Koła Matematyczno-Fizycznego Słuchaczów Uniwersytetu Warszawskiego, 1929); idem, “O logice trójwartościowej”, Ruch Filozoficzny 5 (1920): 170-171.

32 Idem, "O determinizmie", in: Z zagadnień logiki i filozofii, 125. 
first scientist who took it upon himself to build such a general synthesis was Gottfried Leibniz followed by Bernard Bolzano.

Of course, the search for syntheses is closely related to the study of the foundations where the concepts and methods necessary to carry out such syntheses are prepared. Works at the foundations of mathematics also reveal the "channels" that connect mathematics with philosophical issues and reality. To a large extent, the success of the Polish school of mathematics was related to the research of the foundations of mathematics conducted there. Anyway, it was a part of (starting from the midnineteenth century) a tendency which occurred at that time (reference to the ideas and studies of Gottfried Leibniz).

Formal definitions and proofs are not enough in order to study the foundations (in many cases they are also impossible). It is necessary to be open to intuitive thinking that goes beyond current schemes and shows new methods of doing mathematics. Often, however, old intuitions hinder the construction of new theories. That is why it is important to analyze (logically) the foundations, since it shows the mistakes of old thinking and pointing out new forms of argumentation and shaping new mathematical intuitions. Here, we have an example of interesting intertwining and a mutual modification of both, logical and intuitive reasoning.

It is important to note that in the structure of mathematics there are concepts that we can never fully formalize (although they take various formal realizations) and are the absolute foundation of mathematics. Some of them are concepts of the number, harmony, similarity, symmetry, relation, dependence (including functional dependency), structure, symbol, variable, continuity, limit and infinity. From these concepts, mathematics (but also philosophy) derives a wealth of meanings and references, and they are present in both the creative process (discovering new facts, theories, methods of proof) but also in the structure of mathematics itself. They are understood very intuitively, although definitions of some of their mathematical concretions appear. For instance, the concept of harmony acquired a mathematical form as musical harmony or the ratio between numbers (generating new mathematical entities), and the concept of infinity became an infinite series or ordinal numbers.

As we have shown, Janiszewski sought to provide basic definitions (based on set theory and topology) of various geometric objects. All these objects were captured as continua, but in individual cases specifying properties had to be provided. As we noted above, Janiszewski showed that the arc can be defined as an irreducible continuum between two points that does not contain a subcontinuum of condensation. Primarily formed intuition suggested that there are no continua other than arcs that have the property of irreducibility. However, Janiszewski shows the existence of such continua. It is important here to properly "generate" 
subcontinues of condensation. The most typical example is the topologist's sine curve. It is a set of points of a plane that are a graph of the function $f(x)=y=\sin \frac{\pi}{x}$ (where $\left.x \in(0 ; 1]\right)$ together with the limit interval (of density) $[-1 ; 1]$ which lies on the $y$ axis. It turns out that the sine wave is irreducible between the point $(1 ; 0)$ and each point of the interval of condensation. He also constructs a continuum in which each part contains continua of condensation. This continuum is obtained as the limit effect of condensation of singularities on the interval. It is a curve without arcs (so, it is an example of an indecomposable continuum). This construction also allowed seeing the key property characterizing the indecomposable continua: if $\mathrm{C}$ is an indecomposable continuum, then there are three points which belong to $C$, such that $C$ is unreliable between each pair of these points. ${ }^{33}$ The property of unreliability, so characteristic of the interval ( $\operatorname{arc})$, turned out to be a property characterizing such "paradoxical" sets as indecomposable continua. Hidden harmony was discovered and preserved in all continua.

In turn, in order to mathematize the theory of probability, Steinhaus analyzes the game of heads and tails and presents the interpretation of infinite sequences of coin tosses as zero-one sequences. These sequences can be treated as real numbers from the interval $[0,1]$ in the binary notation and then the Lebesgue measure on the interval $[0,1]$ can be used to measure respective measurable subsets of this interval. Steinhaus interpreted these subsets as random events and measures of these sets as their probability. ${ }^{34}$ In addition, a new concept was introduced - "stochastically independent functions" - as an important research tool. ${ }^{35}$ When building the theory of coin tossing, two assumptions turn out to be important in an intuitive manner: the "rightness" of the coin (the probability of the outcome of heads and tails is the same and it is $1 / 2$ ) and "independence" of next throws from each other (if events A and B are independent, then the probability $\mathrm{P}$ of their total occurrence is equal to the product of the probabilities of respective events $-P(A \cap B)=P(A) \cdot P(B)$. If we apply these rules to a sequence of $n$ independent tosses with a right coin

33 Zygmunt Janiszewski, Kazimierz Kuratowski, “Sur les continus indécomposables", Fundamenta Mathematicae 1 (1920): 215.

${ }^{34}$ Cf. Kazimierz Urbanik, "Idee H. Steinhausa w teorii prawdopodobieństwa", Wiadomości Matematyczne 17 (1973): 39-50.

35 These functions (the phenomenon of stochastic independence itself) became the subject of the research program of Steinhaus and his student, Marek Kac. The theory that was being built was meant to be the basis of probability theory and also a tool to show the unity of mathematics (by finding equivalents of this independence in other theories). In the years 1936-1940, a series of six works written jointly by Steinhaus and Kac appeared in Studia Mathematica, that was devoted to stochastic independence. 
( $\mathrm{O}$ - head, $\mathrm{R}$ - tails), we will obtain that the probability of this sequence of events is equal to the product of the probabilities of particular tosses: $\left(\frac{1}{2}\right)^{n}=\frac{1}{2} \times \frac{1}{2} \times \cdots \times \frac{1}{2}$. This is a simply arithmetical law. ${ }^{36}$ What is more interesting, E. Borel proved that almost each number $t$ from the interval [0;1] (i.e. each number $t$ except a certain set that has Lebesgue measure zero) has asymptotically the same amount of ones and zeros in its binary representation. This Borel's arithmetic theorem has its probabilistic counterpart in the considered situation: when throwing a "right" coin endlessly (and if moreover) the throws are independent, then with 1 probability the frequency of heads (or tails) in the limit is equal to $\frac{1}{2}$. It turned out that the same rule applies in both arithmetic and probability theory. In this way, we have reached some hidden harmony underlying in foundations of mathematics. ${ }^{37}$

From research into the foundations of mathematics, fractal geometry was also born (the search for internal symmetry was also a philosophical and mathematical inspiration), created in modern times by Benoit Mandelbrot (1924-2010), a Jewish mathematician from Warsaw. This theory allows us to describe and study objects with irregular shapes and structures that are not available for classical geometry. He applied his theory to study complex physical, biological, and social phenomena, for example to describe the structure of clouds or mountain ridges and to analyze the financial market. ${ }^{38}$ It indicates the occurrence of processes or self-similar structures, showing the hidden order in seemingly chaotic and random phenomena. ${ }^{39}$

Also, many curves and other sets constructed by mathematicians at the turn of the twentieth century (sometimes referred to as "pathological" constructions or counterintuitive) were described as fractals (Cantor's set, Sierpinski's curves and others). The Warsaw topological school specialized in this type of construction. When shaping the abstract concept of continuum, appropriate constructions (e.g. Knaster-Kuratowski

${ }^{36}$ Marek Kac, "Statistical Independence", in: Probability, Analysis and Number Theory, vol. 12 (New Jersey: The Mathematical Association of America, 1959), 21-34.

37 Ibidem, 15-18.

38 In the 1960s, Mandelbrot analyzed the stock market and tried to build mathematical models describing economic processes (including predicting price changes). He noticed then that these processes depart from classical theories (for example, they are not compatible with the distributions described by the Gaussian curve). However, they are subject to a fractal description.

${ }_{39}$ The crowning achievement of this research was the book The Fractal Geometry of Nature published in 1982. It was a kind of a manifesto of "new mathematics" and aroused the interest of representatives of many scientific disciplines. Artificial landscapes, animated films and computer games were created using fractal formulas. 
fan, Warsaw circle, concentrated sine wave, pseudo-arc) were useful, indicating the essential features of compactness and coherence necessary to define the continuum.

\section{The Problem of Mathematical Intuition and the Nature of Mathematics}

I think we can now summarize our analysis. From the activities and views of the mathematicians discussed, a certain insight into the nature of mathematics follows. These mathematicians emphasized that mathematical objects are in some sense present in reality, they are also entities abstracted from reality as well as having the attribute of primality and autonomy. It is due to mathematical objects recognized by our mind that we can, without contradictions, think about reality and look at it rationally. ${ }^{40}$

Mathematics, like other sciences, is not free from intuitive reasoning, which seems to be burdened with uncertainty. In a specific way, however, it combines intuitive and formal elements in its structure. Formal elements, including logical analysis of the foundations, modify and overcome "wrong" intuitions and extend mathematical intuition. The very structure of mathematics (in a classic approach) is based largely on the intuitively arranged system of axioms and postulates (primitive facts). The foundation of this structure is a system of primitive notions and methods of proofs that are accepted and understood by definition. From these primitive facts, which combine the adopted primitive notions, we can deduce further facts (theorems) using axiomatic-deductive methods. Here, there are several key difficulties with which mathematics in the late nineteenth and early twentieth century was faced in a special way (attempts to formalize and axiomatize mathematics itself, as well as other areas of knowledge). Attempts to completely eliminate intuition using the formalization process have proved impossible. The assumption that mathematics is only a game of general concepts and symbols has been rejected because of the occurrence of "indelible" intuition in the foundations of mathematics. This determination alone, of the extent of validity of a given mathematical theory, requires the use of additional (non-formal) tools, including intuition. Moreover, we need to have some interpretative tool and then we need to know how to relate

40 The last period of the development in mathematics has shown in full light the original meaning of the word "mathematics". It derives from the word "máthēma" corresponding to all subjects of study. Mathematics was originally equated with the whole authentic knowledge. This is how the Pythagoreans, the ones who introduce the name in the first place, saw it. 
mathematical theorems to reality. As we have observed, Janiszewski noticed the huge role of axiomatization in specifying the foundations, developing mathematics, showing analogies between various theories, eliminating wrong intuitions and explaining apparent paradoxes, and in building new methods and "purified" intuitions.

It was noticed that intuition also lies in the axiomatic-deductive method itself. To control it and not generate paradoxes, we need to intertwine it with a logical analysis and formalization. The proof (and thus, the path from assumptions to the thesis) consists of a certain finite number of steps, whilst each individual step must be obvious. How does it happen that densification (reducing the "distance" between elements of proof) leads to obviousness? The "appropriately small" step of proof becomes intuitively obvious to the one who is carrying out the proof. The correct proof (without gaps) is one in which all steps have become intuitively obvious. However, often what is obvious to an experienced mathematician is not so to someone who is just starting his adventure with mathematics. Therefore, intuition has to be learned somehow - through exercises, repetition of reasoning, experience, observation of the creative work of others, etc. It is as though, there was something more primitive than intuition or as if it was a combination of various phenomena and experiences. In mathematics, accuracy of reasoning and logical analysis are combined in a specific way with shaping new intuitions and overcoming the old (logic is inseparably intertwined with intuition). Śleszyński's analysis have a special significance for obtaining these conclusions, as well as those by Steinhaus and Łukasiewicz.

However, these are not all areas in which we can talk about mathematical intuition. The last period of the history of mathematics was a synthesis of earlier periods, and it showed their importance and presence in mathematics. In the process of its development, mathematics expanded the domain of its research; new mathematical disciplines and methods appeared. First (in Babylonian and Egyptian times), it was specific (concrete) mathematics, then it reached the level of abstractness (from the Greeks), then, the level of generality (with the creation of the positional notation and algebra), and in modern times - the level of universality. Modern times brought about its further development it became "absolute" knowledge, primary to other sciences, and both, their indisputable foundation and synthesis. Each of these development stages involve a different kind of intuition - concretization, abstraction, generalization and universalization (including optimization, minimization of assumptions and axioms). These types of intuition were present in mathematics, to a certain extent, from the very beginning. However, only the last stage of development made them occur in mathematics.

Each of these stages of development showed a new kind of mathematical intuition and led to some partial "definition" of mathematics. 
And so, the stage of specific (concrete) mathematics is understanding mathematics as a tool that allows us to recognize harmony and order in reality and put them into appropriate structures (it is immersing mathematics in reality and recognizing the mathematics of the world). The Pythagoreans completed this definition by showing the possibility of immersing reality in mathematics (thus, we obtain the isomorphism from the world into mathematics). Due to this process of immersion in mathematics, reality becomes intelligible and mathematical. In the case of abstract mathematics, it turns out that it can be understood as knowledge that can be developed in isolation from reality. And again, general mathematics allows compression of knowledge in concise, formal symbols, formulas and algorithms. Universal mathematics provides methods of reasoning and taking mathematical proofs which are widely used in various sciences and theories. And finally, "absolute" mathematics is an unconditional beginning, the foundation of all true knowledge, and its synthesis.

Based on the above observations, mathematics can be described as:

1. knowledge that allows us to understand reality;

2. autonomous knowledge with respect to sensual reality, but which stays in contact with it during development;

3. an effective tool for modeling the reality;

4. universal science;

5. science that explores objects that are the primary object of thinking and that allow building syntheses. Before man began to count objects, he had to know the idea of number; before he constructed or used a circle, he had to "see" the idea of circularity, etc. Mathematics is therefore a collection of primitive objects of thinking.

As we can see, discovering the nature of mathematics, and, in it, mathematical intuition, is largely intuitive. It requires looking at the creative work of specific mathematicians and tracking the history of mathematics, when new concepts and mathematical theories were born.

A huge area where the work of mathematical intuition can be observed is the foundations of mathematics. Within it, basic structures are studied, which give the possibility of defining or understanding other mathematical objects, and it also checks the scope of applicability of the mathematical method (measuring, computability). Moreover, the correctness of reasoning as well as accepting such and no other assumptions, "obvious" axioms and methods of proof (axiomatization of theory) is examined. In such studies, we do not carry out proof, we instead must refer to the intuition of specific mathematicians, the intuition developed over the centuries in individual and common creative experience, passed on to future generations. Although, at some stage, new mathematical theories may be generated (and it sometimes occurs). This was the case in antiquity, when research on incommensurability 
quantities and measurement issues led to the creation of Eudoksos's theory of relations, and the search for methods for counting great amounts of objects or methods of solving equations gave momentum to the development of algebra. It was similar in modern times. In the nineteenth and twentieth century, many new theories appeared as a result of work on the foundations of mathematics: mathematical logic, set theory, topology, universal algebra, computability theory, metamathematics, theory of category and functors, theory of forcing.

Yet another area where the phenomenon of mathematical intuition can be observed is the aforementioned passing of knowledge - the mathematical education, during which "proper" mathematical intuitions are shaped among students. However, one cannot generally oppose the new intuitions to the older one. Old intuitions have been "overcome" in new research methods and theories, but going down to the foundations of mathematics and seeking validation of new methods of proof we find it again (this is the case with the intuition associated with the previously mentioned concepts of harmony, similarity, symmetry, continuity, infinity). In order to understand mathematical intuition, we must observe how it works in various areas and aspects as well as in various theories and periods of history.

\section{Bibliography}

Brouwer Luitzen Egbertus Jan. 1910. "Zur Analysis Situs". Mathematische Annalen 68: 422-434.

Janiszewski Zygmunt. 1910. "Nowy kierunek w Geometryi”. Wiadomości Matematyczne 14: 57- 64.

Janiszewski Zygmunt. 1918. "O potrzebach matematyki w Polsce". Nauka Polska: 11-18.

Janiszewski Zygmunt. 1916. “O realizmie i idealizmie w matematyce". Przeglad Filozoficzny 19: 161-170.

Janiszewski Zygmunt. 1913. "O rozcinaniu płaszczyzny przez continua". Prace Matematyczno-Fizyczne 26: 11-63.

Janiszewski Zygmunt (ed.). 1915. Poradnik dla samouków, vol. 1. Warszawa: A. Heflich i St. Michalski (including the articles by Z. Janiszewski: Wstęp ogólny, 3-27; Wstęp do stopnia III, 115-141; Równania różniczkowe zwyczajne, 282-298; Równania funkcyjne, różniczkowe i całkowe, 299-314; Rozwinięcie na szeregi, 315-333; Topologia, 387-401; Podstawy gieometrji, 402-426; Logistyka, 449-461; Zagadnienia filozoficzne matematyki, 462-489; Zakończenie, 538-543).

Janiszewski Zygmunt, Kazimierz Kuratowski. 1920. “Sur les continus indecomposables". Fundamenta Mathematicae 1: 210-222.

Janiszewski Zygmunt. 1911. "Sur les continus irreductibles entre deux points". Comptes Rendus, Paris 152: 752-755. 
Janiszewski Zygmunt. 1912. Uber die Begriffe "Linie" und "Flache". International Congress of Mathematicians, Cambridge.

Janiszewski Zygmunt. 1910. "Zur Analysis Situs", Mathematische Annalen: 422-434.

Janiszewski Zygmunt, Kazimierz Kuratowski. 1920. “Sur les continus indécomposables", Fundamenta Mathematicae 1.

Kac Marek. 1959. Statistical Independence in Probability, Analysis and Number Theory, vol. 12. New Jersey: The Mathematical Association of America.

Kant Immanuel. 1998. Critique of pure reason, transl. P. Guyer, A. W. Wood. Cambridge: Cambridge University Press.

Łukasiewicz Jan. 1929. Elementy logiki matematycznej. Warszawa: Komisja Wydawnicza Koła Matematyczno-Fizycznego Słuchaczów Uniwersytetu.

Łukasiewicz Jan. 1920. “O logice trójwartościowej”. Ruch Filozoficzny 5: 170-171.

Łukasiewicz Jan. 1930. "Philosophische Bemerkungen zu mehrwertigen Systemen des Aussagenkalküls". Comptes Rendus de la Société des Sciences 23: 51-77.

Łukasiewicz Jan. 1922-1923. "Interpretacja liczbowa teorii zdań". Ruch Filozoficzny 7: 92-93.

Łukasiewicz Jan. 1961. Z zagadnień logiki i filozofii. Warszawa: PWN.

Molęda Alicja, Zenon Piesyk. 1993. "Przegląd zmian programów nauczania matematyki w szkole podstawowej w latach 1963-1990 w Polsce". Acta Universitatis Lodziensis. Folia Mathematica 6: 25-56.

Omyła Mieczysław. 2010. "Intuicja w naukach formalnych". Edukacja Filozoficzna 50: 139-155.

Pogonowski Jerzy. Intuicja matematyczna w działaniu. http://logic.amu.edu. pl/images/5/54/Mo70jp.pdf. Access: 11.10.2019.

Pogonowski Jerzy. 2012. "Kilka uwag o intuicji matematycznej". Filozofia Nauki 20, 2/78: 107-113.

Pogonowski Jerzy. 2011. "Mathematical intuition - a few remarks". Investigationes Linguisticae 24: 1-24.

Poincaré Henri. 1911. Nauka i metoda, transl. M. H. Horwitz. Warszawa: G. Centnerszwer i S-ka.

Poincaré Henri. 1898. Sur les rapports de l'analyse pure et de la physique mathematique. In: Verhandlungen des ersten internationalen Mathematiker Kongresses. Leipzig.

Poincaré Henri. 1908. Wartość nauki, transl. L. Silberstein. Warszawa: G. Centnerszwer i S-ka.

Poincaré Henri. 1897. “Związki pomiędzy analizą i fizyka matematyczną”, transl. S. Dickstein. Wiadomości Matematyczne 1.

Steinhaus Hugo. 1923. Czem jest a czem nie jest matematyka. Lwów: Księgarnia H. Altenberga.

Steinhaus Hugo. 1938. Kalejdoskop matematyczny. Lwów: Książnica Atlas.

Steinhaus Hugo. 2000. Między duchem a materia pośredniczy matematyka. Warszawa-Wrocław: PWN. 
Śleszyński Jan. 1923. Rozwój pojęć nieskończonościowych. In: Poradnik dla samouków. Warszawa: A. Heflich, St. Michalski.

Śleszyński Jan. 1925. Teoria dowodu. Vol. 1, ed. S. K. Zaremba. Kraków: Nakładem Kółka Matematyczno-Fizycznego U.U.J.

Torretti Roberto. 1978. Philosophy of Geometry from Riemann to Poincaré. Dordrecht: D. Reidel.

Urbanik Kazimierz. 1973. “Idee H. Steinhausa w teorii prawdopodobieństwa". Wiadomości Matematyczne 17: 39-50.

Vuillemin Jules. 1973. Poincaré's Philosophy of Space. Space, Time and Geometry. Dordrecht-Holland: D. Reidel Publishing Company.

Wójcik Wiesław. 2014. Nowe idee topologiczne w pierwszych pracach twórców polskiej szkoły matematycznej. In: Historie matematyki. 257-270. Prague: The University of Prague.

\section{Summary}

In the article, I examine the presence and importance of intuitive cognition in mathematics. I show the occurrence of mathematical intuition in four contexts: discovery, understanding, justification, and acceptance or rejection. I will deal with examples from the history of mathematics, when new mathematical theories were being created (the end of the nineteenth and the beginning of the twentieth century will be particularly important, including the period of establishing the Polish mathematical school). I will also refer to the research (mainly) of Polish philosophers and mathematicians in this field. The goal of the article is also an attempt to understand the breakthrough that took place in mathematics at the turn of the nineteenth century. The analysis also shows, by highlighting the specifics of intuition and mathematical creativity, the difficulties that arise when acquiring new concepts and mathematical arguments. Research goes in the direction of deepening research on the very phenomenon of intuition in cognition, by pointing to the universal nature of mathematical intuition.

Keywords: mathematical intuition, studying of the foundations of mathematics, universality of mathematics, Polish School of Mathematics, mathematics of the turn of the 19th and 20th centuries, mathematics paradoxes

Ministry of Science Financed by MNiSW on the basis of agreement no. 655/P-DUN/2019 (dated and Higher Education May, 7, 2019). Project 2: "Publishing four issues of 'Ruch Filozoficzny' quarterly in English over the period 2019-2020; vol. LXXV - issues 2 and 4 (2019); vol. LXXVI - issues 2 and 4 (2020)"; amount from the DUN grant: 35200 PLN. 